\title{
Phytoprotection
}

\section{Safe Use of Replicating Bacteria in Biological Control}

\section{T.A. Jackson, M. O’Callaghan et T.R. Glare}

Volume 79, numéro 4, 1998

OECD Workshop - Sustainable Pest Management, Safe Utilization of New Organisms in Biological Control. Montréal, Québec, Canada. September 27-30, 1998.

Atelier de l'OCDE - Gestion durable des ennemis des cultures,

Utilisation sécuritaire de nouveaux organismes de lutte biologique. Montréal, Québec, Canada. 27-30 Septembre 1998.

URI : https://id.erudit.org/iderudit/706157ar

DOI : https://doi.org/10.7202/706157ar

Aller au sommaire du numéro

\section{Éditeur(s)}

Société de protection des plantes du Québec (SPPQ)l

\section{ISSN}

0031-9511 (imprimé)

1710-1603 (numérique)

Découvrir la revue

\section{Citer cet article}

Jackson, T., O’Callaghan, M. \& Glare, T. (1998). Safe Use of Replicating Bacteria in Biological Control. Phytoprotection, 79(4), 50-55.

https://doi.org/10.7202/706157ar

\section{Résumé de l'article}

Naturally occurring entomopathogenic bacteria provide an important resource for pest control. Greatest benefit will be obtained from the application of replicating bacteria which can establish in the host's environment and provide long term control. Bacteria developed for pest control are required to be safety tested and registered, yet bacteria are frequently introduced into the environment to enhance plant growth or aid soil processes without regulation. Why then, is the use of insect pathogenic bacteria treated differently? Augmentation of bacteria already present in the environment is unlikely to have any unwanted side effects as application is only changing the spatial and temporal distribution of the microbe and will have little long term effect on the total population. Users of the bacteria, however, will be exposed to the bacterium at a level higher than experienced naturally and potential adverse effects of this interaction should be addressed through Tier 1 safety testing. Non-target organisms should also be tested. If new organisms (exotic strains or modified bacteria) are to be introduced to the environment, their potential effects on the environment should be considered. The question of horizontal gene flow from applied bacteria also needs to be addressed. A better understanding of microbial ecology and Systems for tracking new strains and genes are essential to develop appropriate assessment procedures to ensure the safe utilisation of bacteria in biological control. 


\title{
Safe Use of Replicating Bacteria in Biological Control
}

\author{
T.A. Jackson, M. O'Callaghan and T.R. Glare
}

AgResearch, PO Box 60, Lincoln, New Zealand

\section{ABSTRACT}

Naturally occurring entomopathogenic bacteria provide an important resource for pest control. Greatest benefit will be obtained from the application of replicating bacteria which can establish in the host's environment and provide long term control. Bacteria developed for pest control are required to be safety tested and registered, yet bacteria are frequently introduced into the environment to enhance plant growth or aid soil processes without regulation. Why then, is the use of insect pathogenic bacteria treated differently? Augmentation of bacteria already present in the environment is unlikely to have any unwanted side effects as application is only changing the spatial and temporal distribution of the microbe and will have little long term effect on the total population. Users of the bacteria, however, will be exposed to the bacterium at a level higher than experienced naturally and potential adverse effects of this interaction should be addressed through Tier 1 safety testing. Non-target organisms should also be tested. If new organisms (exotic strains or modified bacteria) are to be introduced to the environment, their potential effects on the environment should be considered. The question of horizontal gene flow from applied bacteria also needs to be addressed. A better understanding of microbial ecology and systems for tracking new strains and genes are essential to develop appropriate assessment procedures to ensure the safe utilisation of bacteria in biological control.
Keywords: replicating bacteria; biocontrol; environment; safety testing

\section{INTRODUCTION}

Mass produced bacteria have been inoculated into the environment for many purposes including pest control and improvement of plant productivity, soil quality and seedling emergence. The commercial use of bacteria for control of insect pests has been dominated by toxin-producing strains of Bacillus thuringiensis $(B t)$ which act as microbial insecticides. $B t$ is considered shortlived in the environment and has been used for many years without adverse effects. Bacterial antagonists and pathogens which are capable of establishing and replicating in the environment have received less attention and provide the focus for this paper. Bacillus popilliae, is the best known example of a recycling, insect pathogenic bacterium. This bacterium has been applied for $>50$ years for control of the Japanese beetle and has been exempted from registration requirements in the USA, because of many years of problem-free use prior to the implementation of microbial control registration requirements. Similarly, the distribution of bacteria $\mathrm{Xe}$ norhabdus and Photorhabdus within their nematode hosts has not been subject to regulatory procedures, even though it has recently been demonstrated that toxins produced by these bacteria are pathogenic to a range of insects, possibly independent of the nematode host (Blackburn et al. 1998). 
Microbial inoculants have been used in many other situations without regulation; various species of bacteria have been used to improve plant productivity by biological nitrogen fixation (Rhizobium spp.), phosphate solubilization and biocontrol of soil-borne diseases. Thus bacteria are released into the environment for many purposes without regulation and this raises the question as to why there should be special concern about bacteria used for biocontrol.

\section{CONCERNS WITH USE OF BACTERIAL INSECT PATHOGENS}

The use of bacteria for insect control is regulated in many countries (Laird et al. 1990). Regulatory procedures for the commercialisation and use of microbial agents are concerned with risks of unwanted side effects, principally to human users of bacterial products and other non-target animals, and also to their effect on the environment. Most registration systems require a maximum challenge, tiered testing procedure, primarily to assess safety to mammalian systems, with reducing emphasis on non-target effects among insects and finally environmental impact.

\section{Relationship to mammalian pathogens and toxicity}

Probably the primary barrier to development of any biocontrol agent for release into the environment is concern over human safety. Past experiences with chemical insecticides have highlighted these concerns. With bacteria used for insect control, the concerns have been compounded by the close taxonomic relationships between some insect and human pathogens (eg. Bacillus and Serratia spp.). However, close examination of this relationship has shown that in most cases, there is a distinction between insecticidal strains and human pathogens. For example, the insecticidal strains of Serratia marcescens differ from the biotypes commonly found causing nosocomial human infections (Grimont et al. 1979). In addition, isolation of bacteria from clinical samples does not always indicate that the organism is a human pathogen. Many bacteria isolated from clinical samples are environmental contaminants capable of invading immuno-suppressed individuals. Many insect pathogenic bacteria (e.g. Serratia, Pseudomonas and Bacillus spp.) are widespread and numerous in the environment yet isolation of insect pathogenic strains or biotypes from farm workers and animals is either extremely rare or completely unknown.

While insect-pathogenic bacteria may be common in the environment, their density in soil and organic matter may be low. Manufacture of highly concentrated bacterial products greatly increases the scale of potential interactions between bacteria and non-target organisms which can lead to human health risks (eg. Samples and Buettner 1983). The question of mammalian safety of high doses of bacteria is addressed by "maximum challenge" testing in current safety testing procedures. Positive results may indicate the need for caution during manufacture but do not necessarily preclude application of the agent to the environment.

\section{Host specificity \\ - non-target effects}

Predicting host range of biocontrol agents has become a controversial issue in recent years, as unexpected nontarget effects have been found after release of some parasitoids and predators. Prediction of host range of a new species is difficult as insect pathogens usually display a wider host range in laboratory tests than occurs in the field. Some species, such as $S$. marcescens have been isolated from a number of insect orders, especially in laboratory cultures, and can show a wide host range (Glare et al. 1998). However, laboratory and field experimentation has shown that this generalist pathogen has low efficacy, requiring high inoculum levels to kill most insects. As such, it is relatively easy to predict that it would be unsuitable for use against insects as an inudative agent because the levels of inoculum required would be prohibitive and pose a potential danger to non-target insects. 
Greater success has been obtained in biocontrol with highly specific pathogens (Jackson 1996). Serratia entomophila is used as a biocontrol agent for grass grub in New Zealand and has never been shown to affect any insect other than the target pest (Jackson et al. 1991). Similarly, Bacillus popillae used for Japanese beetle control appears to show high specificity to the target host. Maximum challenge of closely related hosts and those which live in the same niche as the target insect appears to provide a realistic indicator of potential problems which may arise with application of bacteria for pest control.

\section{Environmental persistence and impact}

The main advantage of replicating bacteria is their ability to persist in the environment and provide long term control of the target pest. This, however, raises questions as to whether there are likely to be any unforeseen consequences of environmental colonisation and how these can be detected and/or predicted.

In order to determine the fate and impact of bacteria following release into the environment, it is essential that the applied bacterium is well characterised and sensitive tracking systems are available. The density at which the applied bacterial population is maintained in the environment can then be estimated and factors affecting its persistence can be defined. Most applications of bacteria for biocontrol and microbial enhancement take place in the soil. The soil is a complex, dynamic medium which, in high fertility agricultural systems contains approximately $10^{8}$ bacte$\mathrm{ria} / \mathrm{g}$. Thus, applied bacteria generally do not constitute more than a small proportion of the total bacterial biomass but it is the effect of applied microorganisms on this biomass that demands attention.

Where the species occurs naturally in soil at low densities, inoculum can be applied to augment the population to a density capable of controlling the target pest or initiating an epizootic of disease among it. Over time, numbers of the applied microbe will return to the natural equilibrium density in the soil. If the organism is new to the habitat or is an improved selected strain, a new equilibrium may be established. An understanding of the microbial ecology of the ecosystem in question is essential in determining the effects of the inoculant on the sustainability and biodiversity in the ecosystem. If the applied bacterium is specific to a particular niche, eg. a particular pest species or a root nodule, it will not survive in the absence of the host and have no long term effect.

The impact of applied bacterial populations on biodiversity and soil processes has been largely ignored because of the difficulties in monitoring specific bacteria within the diverse soil microflora. However, the development of new molecular techniques, including specific genetic markers will improve our knowledge of the fate of applied microbes in the environment. Modelling of microbial survival and interactions provides an alternative approach to raise our level of understanding of this complex environment.

\section{Risk of gene transfer and mutating bacteria}

The registration process treats bacterial-based products as static, stable organisms but this concept is being increasingly challenged. A number of studies have demonstrated that genes, including those associated with virulence, can move between bacterial populations and in some cases from insects, plants and other organisms into bacteria. Evidence is accumulating that these virulence encoding genetic regions (pathogenicity islands) are moving independently and more rapidly than mutation-based evolution of the host cell (Hacker et al. 1997; Groisman and Ochman 1996). Transfer of genetic information can also occur through extra-chromosomal gene exchange, which may not be limited to transfer between closely related species. Several bacterial diseases of insects have been shown to require plasmid borne genes (eg. Glare et al. 1993). The mobility of plasmid-borne genes is crucial in the evolutionary ecology of pathogens, as they may confer instantaneous 
adaptation in changing environments, or they may be costly to the bacteria carrying them (Souzva and Eguiarte 1997).

What is the likelihood or risk of gene flow from applied bacteria to other organisms leading to unwanted side effects? Certainly, genes are moving among bacterial populations more often than previously thought. However, experimental evidence aimed at assessing the likelihood of specific gene transfer remains scarce and it is usually extremely difficult to detect, suggesting that gene transfer resulting in new clones that are able to persist in the environment is not a common event. Plasmid transfer has been shown to occur in insects infected by Bacillus thuringiensis (Adamo and Gealt 1994; Jarrett and Stephenson 1990). More detailed studies are required on both gene transfer in pathogens and mutation rates among bacteria before real estimates of probabilities can be made and risk of gene transfer through application of bacteria can be determined.

\section{SERRATIA ENTOMOPHILA - A CASE STUDY}

Larvae of the New Zealand grass grub (Costelytra zealandica) are susceptible to amber disease caused by strains of the naturally occurring soil bacteria Serratia entomophila and S. proteamaculans. Strains of $S$. entomophila have been developed as the commercial biocontrol product Invade, which provides an interesting case study for the use of replicating bacteria. S. entomophila is commonly found in New Zealand pastures but has rarely been isolated elsewhere in the world. Pathogenic and non-pathogenic isolates of both $S$. entomophila and S. proteamaculans are found in mixed populations in soil where larvae are present.

Selected strains of $S$. entomophila were safety tested for mammalian, nontarget and environmental effects and registered as New Zealand's first indigenous insect microbial control agent (Invade) and the first in the world to be based on a member of the Enterobac- teriaceae (Jackson et al. 1992). Since commercialisation, the bacterium has been applied to over 10,000 ha of pasture with no apparent adverse effects.

The bacterium shows a high degree of specificity for grass grub larvae, with even closely related insects showing no susceptibility (Jackson et al. 1991). Pathogenicity is conferred by plasmidborne genes and appears to be relatively stable. After application to feeding populations of grass grub larvae, the disease consistently establishes in the treated populations and recycles through the grass grub population. The applied strain can be re-isolated from the soil and quantified using selective media, phage typing and DNA fingerprinting. The applied strain has been recovered in high numbers from treated soil in seasons following application, indicating successful establishment and persistence in the treated pastures (O'Callaghan and Jackson 1996).

What has been the impact of application of S. entomophila on the environment? Surveys indicate that the plasmid-carrying, pathogenic bacteria are present at an average level of $10^{3}$ bacte$\mathrm{ria} / \mathrm{g}$ soil (equivalent to $10^{12}$ bacteria/ha) but will increase to more than $10^{5} / \mathrm{g}$ at the peak of an epizootic. Grass grub are present in 1 million ha of New Zealand pastures, thus the total number of plasmid-carrying bacteria is approximately $10^{18}$. The bacterial product Invade is applied at 1 litre/h containing $10^{13}$ bacteria and bacterial numbers tend to stabilise post-application at $10^{3}-10^{4} / \mathrm{g}$ post-application. Thus, the impact of application on total numbers of this species is minimal.

Strain selection has led to use of improved isolates of $S$. entomophila (eg. Strains which are phage-resistant or have greater persistence). These strains predominate after application and have been shown to spread to untreated areas with movement of adult beetles. Once the host population has declined the applied strains tend to die out.

Despite initial concerns about the use of a Serratia spp. for inundative control, a regulatory path was followed for registration without problems. Since 1992, 
10,000 ha of pasture have been treated with $>10^{16}$ bacteria. No occurrence of $S$. entomophila in clinical samples or stock biopsies has been recorded, no new hosts of the bacterium have emerged and no deleterious environmental effects have been identified.

\section{DISCUSSION}

\section{Should naturally occurring bacteria be subjected to regulatory procedures?}

Insect pathogenic bacteria are widespread in the environment and have existed in conjunction with other organisms without causing disease. Therefore, why should bacterial insect pathogens be tested for safety and regulated? The issues which require regulatory consideration include:

- Scale of interaction with producers and users who will be exposed to higher densities of bacteria than would occur naturally. Maximum challenge safety testing will detect potential problems in this area.

- Novel exposure of non-target species to applied bacteria through distribution to new areas or method of application. Testing of related and associated species should indicate potential problems.

\section{Can we adequately determine the fate and impact of applied bacteria on the soil ecosystem? What effect does mass inoculation have on biodiversity and sustainability?}

Effects of microbial addition to the soil ecosystem are largely unquantified. It is important that we develop methods for re-isolation and confirmation of the identity of applied organisms to determine their persistence and effects on soil microbial ecology. Molecular identification techniques, coupled with isolation of DNA directly from soil, provide the opportunity to elucidate soil microbial ecology independent of the culturability of soil organisms. However these techniques are in their infancy and specific molecular-based identification (although technically feasible) has not been completed for most organisms.

\section{Should replicating bacteria be improved by genetic engineering?} Replicating bacteria can be applied as organisms that will spread and persist in the environment, but few have been discovered with genes that are useful for pest management. Genetic engineering offers the potential to insert specific genes with pest control properties into these bacteria. The consequences of new genetic combinations are not well understood and their ability to replicate in the environment has raised some concerns. What is the best pathway to examine these concerns and determine the potential for modified replicating microbes?

\section{Are the current regulatory and safety testing procedures appropriate?}

Current regulatory procedures with tiered testing deal well with potential problems of direct exposure to pathogens but less adequately with potential environmental effects. The greatest potential benefit from bacteria stems from their ability to replicate and persist in the environment thus providing long term control. Empirical evidence indicates that mass produced replicating bacteria can be used without harmful side effects, but appropriate evaluation and testing procedures need to be developed for their assessment.

\section{CONCLUSIONS}

Bacteria are an important resource that should be exploited for insect pest management. Direct toxic effects can be detected through maximum challenge testing procedures. Methods to determine the impact of bacterial application on the ecosystem need to be developed in many cases. While general guidelines can be developed to ensure safe utilisation of bacteria in pest control, registration should proceed on a case by case basis taking into account the properties and ecology of the organism under consideration. 


\section{REFERENCES}

Adamo, J.A. and Gealt, M.A. (1994) Bacterial transfer in soil nematodes, Abstracts of the $9^{\text {th }}$ General Meeting of the American Society for Microbiology, p164.

Blackburn, M. Golubeva, E., Bowen, D. and Ffrench-Constant, R.H. (1998). A novel insecticidal toxin from Photorhabdus $l u$ minescens, toxin complex a (Tca), and its histopathological effects on the midgut of Manduca sexta. Applied and Environmental Microbiology 64, 3036-3041.

Glare, T.R., Corbett, G.E. and Sadler, A.J. (1993). Association of a large plasmid with amber disease of the New Zealand grass grub, Costelytra zealandica, caused by Serratia entomophila and Serratia proteamaculans. Journal of Invertebrate Pathology 62, 165-170.

Glare, T.R., Jackson, T.A., Hurst, M.R.H. and O'Callaghan, M. (1998). Invasive and chronic insect diseases caused by Serratia spp. (Enterobacteriaceae). Proceedings of the $31^{\text {th }}$ Annual Meeting of the Society for Invertebrate Pathology, Sapporo, Japan, pp. 138-142.

Grimont, P.A.D., Grimont, F. And Lysenko, O. (1979). Species and biotype identification of Serratia strains associated with insects. Current Microbiology 2, 139-142.

Groisman E. and Ochman H. (1996). Pathogenicity islands: bacterial evolution in quantum leaps. Cell 87, 791-794.

Hacker, J., Blum-Oehler, G., Muhldorfer, I. and Tschape, H. (1997). Pathogenicity islands of virulent bacteria: structure, function and impact on microbial evolution. Molecular Microbiology 23,10891097.

Jackson, T.A. (1996). Soil dwelling pests is specificity the key to successful microbial control? In Proceedings of the $3^{\text {rd }}$ International Workshop on Microbial Control of Soil Dwelling Pests. (T.A. Jackson and T.R. Glare eds), pp. 1-6.
Jackson, T.A., Glare, T.R. and $\mathrm{O}^{\prime}$ Callaghan, M. (1991). Pathotypic boundaries for Serratia spp. causing amber disease in the New Zealand grass grub, Costelytra zealandica. IOBCMPRS Bulletin, XIV/7, $148-152$

Jackson, T.A., Pearson, J.F., O'Callaghan, M., Mahanty, H.K. and Willocks, M. (1992). Pathogen to product - development of Serratia entomophila (Enterobacteriacae) as a commercial biological control agent for the New Zealand grass grub (CosteIytra zealandica). In Use of Pathogens in Scarab Pest Management. (Eds T.A. Jackson \& T.R. Glare). Intercept, Andover, UK, pp. 191- 198.

Jarrett, P. and Stephenson, M. (1990). Plasmid transfer between strains of Bacillus thuringiensis infecting Galleria mellonella and Spodoptera littoralis. Applied and Environmental Microbiology 56, 16081614.

Laird, M., Lacey, L.A. and Davidson, E.W. (eds) (1990). Safety of microbial insecticides. CRC Press, Boca Raton, Florida, $259 \mathrm{pp}$.

O'Callaghan, M. and Jackson, T.A. (1996). Introduction of mass produced microorganisms into the soil environment. Proceedings of the $3^{\text {rd }}$ International Workshop on Microbial Control of Soil Dwelling Pests (T.A. Jackson and T.R. Glare, Eds.), pp. 89-94.

Samples, J.R. and Buettner, H. (1983). Corneal ulcer caused by a biological insecticide (Bacillus thuringiensis). American Journal of Ophthalmology 95, 258-260.

Souzva, V. and Eguiarte, L.E. (1997). Bacteria gone native vs. Bacteria gone awry?: Plasmidic transfer and bacterial evolution. Proceedings of the National Academy of Science 94, 5501- 5503. 